\title{
Perspectives - Social Change from the Inside Out. From Fixation to Foundation. From Competition to Change
}

\author{
Cornelia C. Walther ${ }^{1}$
}

Received: 5 July 2020 / Accepted: 5 October 2020/ Published online: 3 November 2020

(C) Springer Nature Switzerland AG 2020

\begin{abstract}
After a brief overview of the author's journey as a humanitarian and researcher, this article offers an introduction in the why, how, and what of a new multidisciplinary paradigm to understand (and improve) human behavior at the individual and collective levels called POZE. The logic of POZE underpins five books that appear at Palgrave/Springer in 2020/21. It is based on the understanding that human existence results from four dimensions, soul, heart, mind, and body, which find their expression in aspirations, emotions, thoughts, and sensations. Through their four-dimensionality individuals are symmetrical to the four dimensions that shape the society, which they are part of. Individuals are the micro entity of a four-dimensional collective reality that encompasses communities and institutions in the meso-dimension, and countries and economies in the macro-dimension. Altogether micro, meso and macro are integral parts of the meta dimension, Planet Earth; the latter also includes non-anthropocentric aspects such as Nature. POZE provides insights about the multiple dynamics that shape our individual and collective experience. Moreover, it provides practical guidance to optimize the interplay between them. As a result of this understanding, it posits that change is possible. Moving towards a fair inclusive world, characterized by a life of quality for everyone 1) is at reach; 2) is achievable; 3) involves everyone as both a right-holder and duty-bearer; and 4) is to the benefit of everyone. POZE has four meanings: it i) translates as 'inner peace' from Haitian Creole, country where the dynamic began in 2017; ii) is an acronym that encompasses the four core concepts of the paradigm (Purpose, Om, Zoom, Expression); iii) is a representation of the four outcomes of the logic (Perspective, Optimization, Zenith, Exposure); finally it iv) stands for an exercise to nurture inner peace daily (Pause, Observe, Zoom in, Experience). These will be explored further in the article.
\end{abstract}

Keywords Transformation - Paradigm - Development - Aspirations · Emotions · Experience $\cdot$ Behavior $\cdot$ Planet $\cdot$ Dynamic $\cdot$ System $\cdot$ Haiti $\cdot$ Influence $\cdot$ Intention

Cornelia C. Walther

cornelianow@hotmail.com

1 Tuebingen, Germany 


\section{Introduction}

To achieve a world with more opportunities and a better quality of life people must want to be part of social solutions. To this end, the $\mathrm{POZE}^{1}$ paradigm addresses social change from different angles that together form a circular embrace of the four dimensions that determine human experience and expression. While the underpinning logic for all of them is the same, Purpose for Power concentrates on the empowerment of the individual, independent of an institution. Compassion for Change focuses on individual reconnection as a means towards institutional cultural change. Influence for Impact is geared towards the systematic use of individual and collective decision-making processes to shape behavior. Common to all is the Honesty for Humility approach, which is about personal authenticity, also called 'leadership'.

The worldview that underpins the POZE paradigm, has arisen organically as a result of my becoming. It offers a perspective to understand and optimize human behavior. We are part of a context and whatever we are, do, and become is not only influenced by our surroundings but we also influence our surroundings. A central result of POZE is that this influence can be understood and optimized. Once we acknowledge the multiple undercurrents that determine our existence, we can use this awareness for our own good (and that of others). When we know what affects our thinking and feeling, our desires and dislikes, and ultimately our behavior, we are no longer the victim of inbred instincts. Usually, we know inside what is good for us, and for others; and this intuitive knowledge is present even while we are doing exactly the opposite. The aim of POZE is to bring the interplay between the visible and the invisible, the interaction between what we want and what we do, to the surface; to make it approachable. Once we have seen how the model operates and why it works across cultures and countries, we conclude with a brief overview of the consequence that a POZE perspective has on the society that emerges from COVID-19.

A society that caters to the needs of everyone is beneficial for each of us. In order to make it happen, people in society (us) must grasp this possibility and the duties that derive - - but not just intellectually. They (we) must genuinely want to make it happen.

Change happens from the inside out, starting with the aspiration of individuals to do something that matters not just for them and their closest kin. This aspiration opens a doubled window, because it entails on the one hand the desire to do something, and furthermore to do it for/with someone else. Once an internal change of attitude and appreciation has begun, it is nurtured from the outside in. Every small concrete action that manifests the new understanding contributes to the gradual emergence of new beliefs and behavior patterns. Personal transformation occurs as organically as everything else.

As I am writing this article I am in New York, the national epicenter of the international epicenter, of COVID-19. It is a surrealistic scenario where horror and apparent normality reside side-by-side. The Pandemic that engulfs the world since the onset of 2020 has lain bare a class conundrum that has simmered under the surface for

\footnotetext{
${ }^{1}$ POZE has four meanings: it i) translates as 'inner peace' from Haitian Creole, country where the dynamic began in 2017; ii) is an acronym that encompasses the four core concepts of the paradigm (Purpose, Om, Zoom, Expression); iii) is a representation of the four outcomes of the logic (Perspective, Optimization, Zenith, Exposure); finally it iv) is stands for an exercise to nurture inner peace daily (Pause, Observe, Zoom in, Experience)
} 
decades. Growing quietly in our midst we knew it was there but for many of us it was easy to overlook it. No longer.

COVID-19 pulled the veil of chosen blindness that had lulled many of us in a lukewarm want-belief that the system that we evolve in works well. If the expected sum is 100 but the actual outcome is 30 , something is uneven. Why do we accept it simply because we are part of the 30 ? Once we are not just looking but actually see, we realize that every day illustrates the different faces of inequity. Every one of us is a potential perpetrator; because if we are not doing something to solve a problem, we are part of it. COVID-19 represents a precious opportunity to change who we are, individually and as a society. We can seize this momentum of a collective wake-up call to make a difference. POZE is about individual and collective change to expand the collective sum to 100 .

\section{The Journey to POZE (my Path)}

The POZE paradigm has evolved organically as a result of the author's experience, education, and research. A short overview of her journey is provided to illustrate how POZE works.

Born and raised in Germany, in a middle-class family, I won the lottery ticket at birth. It set me on the right track from the start. Growing up it seemed obvious from the start that I had to give back what I had been given. The need to justify why I deserved the privileges that had been placed in my lap from the onset was always there. This led to a range of seemingly incongruent career choices which were all motivated by the same desire, making a difference by making the world happier. Only recently, now in my forties, I came to see that life is not about doing but being. It is not about giving our best but becoming our own best self. We will look at that in section two.

To begin with I chose to be an actor. Not with the aim of fame and fortune but driven by the belief that if we can show people how the world could be, they would want to make it happen. I pursued this line of life for a while until 1 day I realized that I had hit a wall. I could not spend the rest of my existence saying what others had written, doing what I was told to do; all the while operating in a vacuum of make-believe that never left the stage. I quit. After a short stint as an au-pair in Brussels where I learned French, I started to study law in Germany while taking care of my ailing grandmother. I believed that I could develop laws to protect those that cannot protect themselves. After 3 years I went to France to graduate in international law. As it turned out, the university where I graduated had a European Master of Arts program on humanitarian assistance (NOHA). Seizing this first of a series of coincidences (that are not), I stayed in France pursuing in parallel another master's degree in international crisis law to maximize the opportunity to learn. However, I realized that the law is only as valid as the willingness of those who implement it to apply it faithfully. Without such willingness a large gap between theory and reality materializes. Thus, I started to think of shifting my focus from humanitarian law to humanitarian work on the ground.

Consequently, 2 years later and with my two brand new degrees I went to Mali with the United Nations World Food Program (WFP). I ended up staying not 6 months but 3 years. It was dire and delightful. Once again, I was fortunate in so many ways. Having overcome a disease that brought me to the hospital (and nearly to an early grave) barely a 
month after I had arrived in the country, I found friends and insights. My boss was the type of supervisor that every young humanitarian worker should have at least once. Committed to work and life simultaneously, he showed humanity in every fiber of his body. It was a time of learning that helped me groom the stamina that I needed as I moved on. Mali was the beginning of nearly two decades on the ground, in some of those countries that appear as the top of the worst from an outsider perspective. Working with the United Nations Children Emergency Fund (UNICEF) I went to Chad, working in the border area to Darfur, and Afghanistan, the Democratic Republic of Congo, and Haiti. This range of countries was a question of choice and luck. Being in these places, which are not only afflicted by humanitarian disaster and chronic poverty, but also by a gloomy image in the public eye, allowed me to get a new perspective. It offered me a glimpse of the beauty and the resilience of individuals of all ages; not as words and concepts but as an everyday experience. The people I met had been placed in a life where survival is not a given, and where every day may be the last. And yet they not only just got by, they found the strength to smile and share. From stories to tea, from bread to coffee, so many moments in places that are decried as places of terror and despair have a cherished niche in my heart; because of the individuals who shared their time with me.

While stationed in DRC, I did my doctorate by distance with a Law University in France while doing teaching stints in their humanitarian master's program. Seeing, every day, the gap between theory and practice, my dissertation looked at the responsibility to make children's rights come true. About 700 pages later I had answered the question I had been determined to answer (does an individual and collective responsibility to address the needs of all children everywhere exist as an obligation that precedes human rights law? Yes!). However, I was left with an even bigger question. But if individuals and governments are conscious of their responsibilities, and do not act accordingly. What must change? If despite the multitude of legal conventions that enshrine equal entitlements for all, and thus a fair chance in life, billions are deprived while millions are surfing on a surplus, then something is missing. That set me up for the quest that eventually led to POZE. How can we make people want to be part of social change, and find happiness along the way?

As time went by the questions that I had set out with as a young humanitarian grew and got company. While working on the ground, I witnessed too often the gap between rights and reality, between mission and manifestation, between possibility and practice. Humanitarian and development programs are precious and necessary, but increasingly I felt that those who were mandated to implement them remained underneath their potential. It is easy to criticize and hard to improve. Thus, I am far from joining the camp of those who claim that aid agencies should stop operating. Rather my question is what must change inside to make these organizations whose work is direly needed more impactful outside.

In 2017 while I was working in Haiti I began to develop and test the prototype of a methodology that eventually became POZE. Translated from Haitian Creole the word stands for 'inner peace'. It was coined by colleagues who experienced the approach first-hand. As it turned out, yet another coincidence, the four letters of the acronym also encompass the four core concepts that underpin it. Purpose, the quest for meaning that drives human existence, "Om", the widely recognized word for emotional unity, Zoom, a mental focus on the essential, and Expression, the manifestation of our beliefs in the world. 
In 2018 I went to New York to help design UNICEF's global communication and advocacy strategy. Around the same time, I was offered a position as a researcher and lecturer at Deakin University's Center for humanitarian leadership. I decided to take it after completing my task in New York. For my friends and colleagues, the move from a well-paid stable UN career to an academic job with half the salary at the other side of the globe appeared drastic. Since the alternative that I had been playing with in my head for a while was to quit my job without another one to replace it, the move to academia felt like a soft transition. It offered me a transition from the work that I loved but increasingly doubted, to a position prone to improve that field of work. But it was not meant to be.

Due to visa issues the move to Australia did not happen (though I kept on collaborating with Deakins as a pro bono coach for humanitarian leaders.) But it was too late to continue as before. Once I had popped the bubble of my comfort-zone, it was impossible to reconstitute it. In 2019 I took a sabbatical and began to put POZE to paper. Once again, an apparent coincidence turned out to be a blessing in disguise. The books that brought this article about would not have been written by now if everything would have worked according to plan.

\section{What is POZE (Model)}

This section explains the twice four-dimensional logic that underpins the POZE paradigm at the individual and collective level.

How we live as individuals in this World is influenced by the four dimensions that shape our being: soul, heart, mind, and body. Their expressions are aspirations, emotions, thoughts, and sensations. This intrinsic dynamic renders individuals a symmetrical representation of the society they evolve in.

Society is composed of 7.8 billion individuals, each of them a complex microdimension. The next higher level is the meso-dimension, covering families, communities, and sub-national institutions from small to large, that individuals (in)voluntarily and (un)knowingly belong to. The macro-dimension encompasses micro and meso in the form of countries, economies, and cultures. Altogether micro, meso, and macro form the meta-sphere which furthermore includes supranational organizations such as the United Nations, and non-anthropocentric features such as Nature. Engaged in an ongoing spiral dynamic, from the center to the periphery and from the periphery inwards these multiple dimensions continuously interact and influence each other.

At the individual level there is a constant set of connections along the continuum of the layers; a spiral dynamic unfolds, connecting the physical and the inner realm in a constant flow, which operates in both directions. Aspirations (soul) influence emotions (heart) and thoughts (mind), and thereby decision-making processes. These decisions manifest in the form of expressions (body), words, actions, or gestures that culminate in experiences (body) through physical and sensorial impressions. These experiences generate memories (mind) and emotions (heart) that will be drawn upon in the future when a similar situation requires an (re-) action or decision. Action for others leads to a harmonization of behavior, emotions, thoughts, and the aspiration of living in line with one's values. The resulting experiences confirm a positive self-image, which come with positive emotions and peace of mind. 
COVID-19 has revealed that everything can change, always and unexpectedly. Amid this omnipresent uncertainty we can however identify and influence the factors of certitude that exist unfailingly. Four principles apply to individuals and society alike: 1) Connection: Everything is linked to everything else. Nothing happens in a vacuum. 2) Change: Everything always evolves. Nothing stays the same forever. 3) Continuum: Everything is part of a scale on which it eventually transforms into something else. Nothing occurs secluded from the rest. 4) Complementarity: Everything stands in complementarity to something else. No phenomenon occurs without a counterpart that completes it.

Internally the interaction between our aspirations, emotions, thoughts and sensations influences who and how we are, what we do, and how we interact with our environment. Externally, the mutual interplay between individuals and institutions shapes the society that we evolve in, and the individuals in it. A word on each of these dimensions follows as the basic structure to organize subsequent reflections.

\section{Individual Dimensions}

Since Plato, philosophers have described the decision-making process as either rational or emotional (Lehrer 2010). However, neuroscientific findings increasingly prove that that our best decisions are a blend of both feeling and reason, depending on the situation. As Antonio Damasio states, "We are not thinking machines that feel; rather, we are feeling machines that think” (Damasio 2012). To influence decision making processes, it is crucial to not only think about what we feed the brain, but to also carefully reflect on how the different parts of the brain respond. Within this perspective, it is important to consider an additional angle: error. Research shows the existence of 'systematic' errors within the machinery of cognition, which cause irrational choices independent of 'corruption' by emotions (Damasio 2012).

What we think and do leaves physical traces in our mental hardware. (Doidge 2011). Emotions are fundamental in determining our opinions, decisions and deriving from them our behavior. Thoughts and emotions influence each other mutually.

The soul represents the essence of who we are. ${ }^{2}$ It is the core of our being and embodies our aspirations. The desire to find meaning in everyday existence influences what we feel, think, and do. (Frankl 1946). The quest of WHY, the need of purpose is anchored here. It naturally relates to the connection with other beings, and the inherent desire of a shared existence, which involves the sharing of resources (Nowak 2011).

The second dimension is our emotions. Metaphorically speaking they are in the heart. They influence how we feel about ourselves, others, and life overall. WHO we are and what we do, is only partially the result of rational choices; our decisions are significantly influenced by our feelings. (Lehrer 2007).

Emotions are commonly defined as "any conscious or unconscious experience characterized by intense mental activity". ${ }^{3}$ Physiologically speaking, these mental

\footnotetext{
${ }^{2}$ In its most basic sense, the word "soul" means "life," either physical or eternal. (Merriam Webster) The primary distinction between soul and spirit in man is that the soul is the animate life, or the seat of the senses, desires, affections, and appetites. Whereas the spirit is commonly used as a reference to the part in humans that seek a connection to God.

3 "Emotion is any mental experience with high intensity and high hedonic content (pleasure/displeasure)". See Cabanac (2002).
} 
activities are mostly processed in the Amygdala part of the brain (Bzdok et al. 2012). They can be understood, influenced, and used systematically in the process of personal and collective change dynamics.

In basic terms, emotions can be considered and studied as "simple patterned behavioral and physiological responses to specific stimuli" (Gratch and Marsella 2003). Neural and psychological research, however, increasingly suggests that there is a tight integration of emotional and cognitive processes, with emotions playing a central role in cognition and decision-making (Damasio and Descartes 1994).

The third dimension of our being is the mind. Thoughts influence our emotions and aspirations, our physical experiences and expressions; and are influenced by them (Kahneman 2007). Thoughts, ideas and opinions result from an intricate mix of genetic disposition, education, beliefs, memories, upbringing, and environment. Anchored mostly in the mind, they are influenced by hardware aspects such as neurological pathways, hormones, blood-supply, nutrition etc.; and by software elements such as our past and present expressions and experiences. Thus, they stand in constant connection with the rest of our being. HOW we think in the present is not only influenced by WHO we currently are as a person; it is influenced by our past being, and it influences who we evolve into in the future.

The fourth dimension is the body, which is one the one hand the outer casing that connects and separates our internal and external realm; and on the other hand, a channel through which we relate to the world. What happens in the physical space has direct impact on our mental and emotional evolution. As an interface between the inside and the outside, the body allows us to experience the World and express ourselves in it; including in the relationship with other human beings. Physiological aspects experienced via our senses impact the way in which we think and feel. The signals taken in by our senses are direct, such as heat or colors, and indirect such as words and interactions with others; they are external, looking at everything outside, and internal, like hunger or pain. Invisible factors such as the state of our microbiome, blood-sugar level, hormone balance, immune system etc. affect our ability to reason, our mood and our attitude towards the world. (Gordon 2009).

Our present mind-set and personality (WHO we are) influences how we experience the world. And how we experience our environment influences how we express ourselves in it (WHAT we do). It is a two-way road, whereby our physical action is influenced by our mental set-up and it influences it in turn (Doidge 2011).

Nothing happens in a vacuum. The body reflects our internal circumstances. Conversely, our experience of the environment impacts our internal circumstances, shaping our perspective of the World and hereby our reaction to it. Whatever happens at the center radiates out, like a stone cast into the water. Whichever state our internal realm is in - our emotions and thoughts, which are influenced by our aspirations, impacts our perception of and interaction with the outside (Figure 1).

Life is like a mirror. Whatever happens around us has a counterpart inside of us; and inversely, what happens inside has a matching part outside. The four dimensions that influence our personal experiences and expressions reflect the four-dimensional dynamic that shape society to which we turn in the next sub-section. 


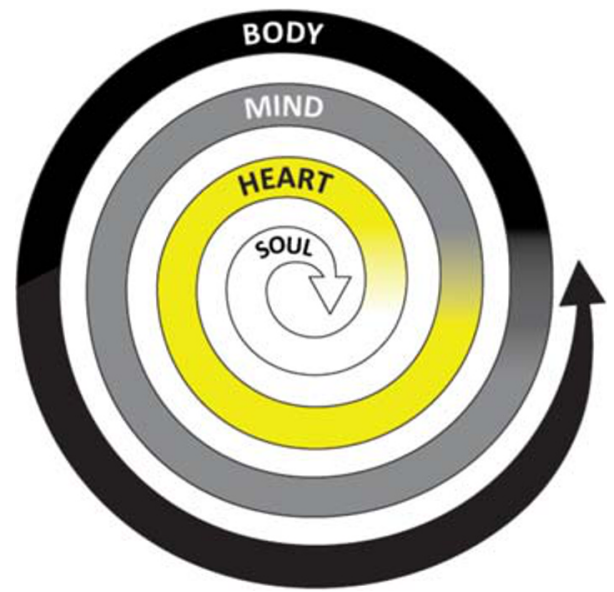

Fig. 1 Everything is connected, from the inside out and from the outside in. Our soul finds its expression in our aspirations. These influence the heart, which is the source of our emotions. How we feel impacts our mind. How and what we think impacts our overall wellbeing, and our behavior. From the inside out and from the outside in. The body is the interface between our inner and outer realities. Experiences influence our mind and heart, our thoughts and feelings. Physical experiences influence our inner realm, while the latter shapes what our expressions, our attitudes, and our behavior in the outside world is and will be

\section{Collective Dimensions}

The micro level refers on the one hand to the four-dimensional internal composition of every individual's being; on the other hand, it is a fundamental piece (the individual) of society. Every person is at the same time part of various meso-entities, different types of institutions and communities (e.g. family, church, workplace, school, political party, or sports-club). These meso-entities organize and unite individuals within entities that have a group identity, distinguishing them from others; they also function as an intermediary between the individual person and the subsequent macro level; the latter encompasses the economic, political and, cultural spheres that we, and our lives, evolve in. Respectively and combined these three dimensions form part of the meta-dimension which also covers Nature. It should be noted here that the meta level includes also to supra-national organizations and entities such as the United Nations, which have a global mandate and impact.

Micro, meso, macro, and meta dimensions mutually influence and shape each other. Whatever happens in one dimension has repercussions within and upon the other ones. Immediately or eventually, directly or indirectly. From here on we will look at the use and application of the POZE model and the implications that derive from it.

How we deal with this set-up is a matter of choice. We can focus on one dimension while leaving aside the others. Alternatively, we have the possibility to put the panoply of pieces into a holistic vision, which capitalizes on synergy, and systematically influences their causal interplay. We can leave the outcome of the constellations that influence our existence to pure chance. Then again, we can choose to consciously influence them in view of results that lead us closer to our medium-term and final goals. Acknowledging, analyzing, appreciating, and methodically addressing the twice four-dimensional (i.e. the four internal dimensions at 
the individual level and the four collective dimensions) dynamic that shapes our reality is challenging, but possible. It may appear like an overwhelming endeavor to look beyond personal interests, and in the case of governments of national interests. What we know and have today grants us a power that is far beyond anything previously imaginable. The question is to translate this potential into practice.

\section{Understanding and Influencing Behaviour}

Our perception of reality is the result of two complementary forms of experience: direct experience, via our five senses (seeing, hearing, smelling, touching, tasting); and indirect experience, with the intake of information (listening, reading, observing). This information is filtered through our intellectual processes and existing belief systems. Emotions drive us on a subconscious level.

Rooted in our past, these emotions influence what we desire for the future. Individuals' past experiences influence their present mood and mindset, as well as the values that dominate their belief system. Beliefs about a certain issue determine our emotions and therefore shape our attitude towards the situation we are currently in. This influences our behavior, which results in an experience that either reinforces or changes our beliefs and impacts our subsequent emotions. (e.g., I believe that I am an awful runner. Therefore, I enter the marathon with the conviction that I will fail, which results in high stress that undermines my performance. The result is poor and confirms my belief.)

Awareness of this connection, combined with attention to emotions, bodily sensations, and thoughts, offers individuals a tool to consciously work on their beliefs and thereby change their experiences. This cycle of mutual influence is ongoing and constant. Aspirations influence Emotions. Emotions influence Thoughts, and therefore Decisions. Decisions result in Expressions that involve Sensations, forming Experiences. Together, these elements create memories. If repeated many times, recreated patterns become habits that gradually result in certain character-traits, which in turn trigger certain emotions during certain situations. It is a spiral that operates in both directions, from the inside out and from the outside in.

Once we understand the dynamics that underpin our own behavior, we start to understand the behavior of others. This two-folded understanding enables us to influence both, our own behavior, and theirs.

In terms of intensity and impact the various stages of influencing others can be placed on a 'Scale of influence'. (Walther 2020b)

The first and lowest stage is Informing. It provides the mind with facts and figures. Yet, no matter how much information we have about a certain issue, emotional impulses influence whether our attitude shifts from knowing about it, to caring about its implications and about those who are affected by it, to genuinely wanting a change of this situation, to actually getting proactively engaged to do something about it. Thus, the second stage involves inducing emotions. The heart is pulled in through stories, images etc. Still, the resulting attitude towards the issue is passive. The third stage is to intrigue the person to rethink their current belief system by providing them a perspective that pushes them out of their acquired mental space. The fourth stage is about igniting. It is anchored in offering the spectator the opportunity to experience what change feels and looks like if someone else does. Thus, change becomes 
tangible and relatable. Once action (the result or bodily expression of change in mind, heart, and soul) is taken, a fifth stage is activated which lies beyond the scale. It is outside the scale because as observers turn into players their action has the potential to inspire other observers to get involved. A new scale begins with the potential to reach further people.

An all-encompassing understanding of the human behavior is a major asset to optimize our behavior in view of our own happiness, the happiness of others and the overall functioning of the communities that we are part of.

Every day is a test, whether we are mature enough to use our own personal influence for a common good.

\section{The Logic underneath}

The following is a very succinct overview of the multidisciplinary foundation that this paradigm and the related change methodology draw upon.

When our soul, heart, mind, and body are aligned we enter a state of inner peace, from which the harmonization of our relationships with others flows effortless. Understanding the direct and indirect impact that the interplay of aspirations, emotions, thoughts, and sensations has on ourselves, and on our environment, allows us to systematically develop the influence that we need. Instead of being influenced, we influence. The results of such multidisciplinary cognizance are to our own benefit and can be turned to the benefit others.

\section{Change from the Inside out}

Neuroimaging shows the physiological construct that connects thoughts, emotions, and physical feelings within shared neural networks. ${ }^{4}$ There is a functional architecture of diverse mental states that were previously seen as intangible. The brain perceives our mental states through situated conceptualizations, which combine three sources of stimulation (Barrett 2009). The first is sensory stimulation from the world outside the skin. Exteroceptive sensory signals come from light, vibrations, chemicals, sound, etc. The second type of stimulation comes from interoceptive sensory signals within the body (the internal milieu, which includes the microbiome that resides in the gut and has a direct connection to the brain) The third source of stimulation is prior experience, also referred to as memory or category knowledge, that the brain makes available in part by the re-activation of sensory and motor neurons. (Bzdok et al. 2012).

These three sources - sensations from the world, sensations from the body, and prior experience, are continually available. The brain networks that process them can be thought of as the basic ingredients that form all mental processes. Whatever we experience as emotion, cognition, or perception results from the combination and weighting of these ingredients. In contrast to previous beliefs, recent studies show that there is not one network for each emotion or even for the experience of emotion versus cognition. Rather, they are all part of the same network, a living spiderweb that connects every aspect of our inner and outer experience of that state called reality

\footnotetext{
${ }^{4}$ See. above "States of mind"
} 
(Barrett 2006). Humans have evolved to decode their environment (Fliesler 2017). We unconsciously analyze what is happening long before cognitive judgment sets in. Built into the hardware of our body and brain, this intricate mechanism allows us to sense approaching events that would otherwise evade our awareness (Lehrer 2010); alerting us to patterns in our environment that are so subtle that we cannot consciously detect them. The resulting 'gut instinct' is crucial for survival, but fallible. The brain's ability for pattern recognition and pattern identification may trigger suspicion of unfamiliar things or cause us to be overly reactive to people who remind us of someone (Dhaliwal 2011). The interpretation we make of an event depends on our prevailing mind-set, which is influenced by both our past experiences, including upbringing and education, and current exposure to influences like opinions and social currents.

During the first months of a child's life only the right frontal lobe is active. It is this brain component that will eventually specialize in visual-spatial perception, creativity, and emotions. During the initial phase of life, we experience and express our emotions directly (Golemann 1996) because the inhibition of the left frontal lobe is not yet coming into play. Our internal filter mechanisms are still being established. A baby cries when it is unhappy and laughs when its happy, without a detour via the learned 'right/wrong' department of social expectation. As we grow up, our being shifts attention from the world to the self. Gradually, we are not just reacting to the world, but proactively acting in it.

Daniel Kahneman's explanation of two parallel, yet complementary thought systems helps us understand how to use intuition with care (Kahneman 2011). "System 1" is fast, instinctive, and emotional, used in situations requiring fast reaction because we face (or seem to face) immediate danger. "System 2" is slower, more deliberative, and more logical. While the first is automatic, the second needs concentration and agency to process thoughts. It is part of the conscious self, which makes choices, has reasons, and holds beliefs.

In the same way in which the intake and analyses of sensorial inputs happens via a spiderweb that embraces the whole body, the brain is far more versatile than presumed for a long time. (Kahneman 2011). The right/left separation that was long considered as a valid schematization of the brain's operating system is only part of the answer. Recent evidence is consistent with a psychological constructionist approach of the mind: a set of interacting brain regions commonly involved in basic psychological operations of both an emotional and non-emotional nature are active during emotion experience and perception across a range of discrete emotion categories. ${ }^{5}$ (Lindquist et al. 2012).

Furthermore, the brain can change its own structure and function in response to mental experience, due to neuroplasticity (Doidge 2007). The brain's capacities are dynamic and trainable: "The brain is a far more open system than we ever imagined, and nature has gone very far to help us perceive and take in the world around us. It has given us a brain that survives in a changing world by changing itself."

While advantageous in some cases, neuroplasticity also has a downside when it comes to the efficiency of opioids for chronic pain treatments. As the plastic brain's own opioid receptors grow saturated, it produces new receptors which are less sensitive

\footnotetext{
${ }^{5}$ Since the onset of psychology experts has wondered which parts of the brain are responsible for which functions. Commonly two theories are under discussion. The locationist approach (i.e., the hypothesis that discrete emotion categories consistently and specifically correspond to distinct brain regions) and the psychological constructionist approach (i.e., the hypothesis that discrete emotion categories are constructed of more general brain networks not specific to those categories). Recent evidence supports the latter. (Lindquist et al. 2012)
} 
to the medication, rendering the patient more and more dependent on higher and higher doses. However, once understood, neuroplasticity can serve to steer a patient away from opioid-induced brain sensitivity. (Doidge 2007).

\section{Change from the Outside in}

Action and attitude shape each other, and hereby our emotions. When we aspire to be kind, generous, patient or a good listener; than we can start to induce this character-trait long before it feels like a natural manifestation of our character. The brain is our best friend when it comes to the design and implementation of Who we want to be.

The outside-in change dynamic works in smaller and larger ways. On the one hand bodily posture impacts our physical, mental, and emotional status. It influences our mood, memory, behaviour, and stress levels. It not only eases the symptoms of depression but lessens self-focus (Cuddy 2015). Physiologically speaking a physical pose that reflects an attitude of power - upright, square shoulders, and head up sends a signal to the brain; a neural impulse which turns into an actual, physiological response that boosts brainpower. Furthermore, posture affects hormone levels - decreasing cortisol and increasing testosterone, the latter being associated with self-confidence (Veenstra et al. 2017). On the other hand, our action impacts our experiences and memories which eventually reshapes our mindset; both metaphorically and practically speaking.

The best way to become part of social change is to be proactive, plunging into new projects and activities, interacting with very different kinds of people, and experimenting with unfamiliar ways of getting things done (Ibarra 2015). The traditionally assumed logical sequence - think, then act - is often reversed in a personal change process. Paradoxically, we only increase our self-knowledge in the process of making changes.

Priming new habits can begin with actions that are performed consciously, even if the underlying motivation is not intuitive. Gradually, the resulting experiences will result in new habit patterns in the mind. Especially in times of transition and uncertainty, thinking, and introspection may follow physical experimentation - not only vice versa. Transformation involves action, which is likely to cause discomfort if the intended change requires the individual to move out of his/her comfort zone. Actually, it is only outside of this zone's border that personal change occurs. As these new unacquainted behaviors are performed repeatedly, they induce changes in the physical brain circuitry thanks to neuroplasticity (Doidge 2007), which makes them ever more permanent until they feel 'normal'.

Social norms, or mores, which are the unwritten rules of behavior considered acceptable in a group or society, result from the interplay between beliefs and behavior, between individuals and larger communities (Bicchieri 2017). In the same way that poverty and violence are condoned in some parts of the world, avoiding and addressing these issues individually and collectively can become a new norm.

Humans are hardwired to cooperate, and whatever one does for others has benefits in both directions, for the one who acts and the one who's acted for. Moreover, benefits of pro-social action occur on four levels. The very act of giving back to the community boosts a person's happiness, health, and sense of physical well-being (Plante 2012). Beyond benefit for the one who acts and the one who is acted for, others who witness altruistic acts experience renewed hope, appeasement, and the desire to take similar action (Ramey 2016). From such an expanding attitude of kindness and care among individuals, society overall benefits as the occurrence and acceptability of inequality and deprivation shrink. 


\section{Applying the POZE Paradigm}

This section offers a way for individuals and institutions to apply POZE in their, practice and activities.

The previous section covered the logic that underpins the POZE paradigm. The following pages provide an overview of its application. Having established WHAT it is and WHY it works, we will briefly look at HOW four approaches use the posited principles in the pursuit of clearly defined goals - the empowerment of individuals ( $\mathrm{P} 4 \mathrm{P})$, the transformation of institutional culture in the non-profit sector and a shift of leadership perspective beyond influence to inspiration and the expansion of influence to build social good at scale (i4i).

Each approach is anchored in one particular dimension, yet they operate on the interplay of all four dimensions. While distinct in their scope, with differing prime audiences, each approach is anchored in the same understanding that individuals have the power to change their own destiny and make a difference in the lives of others. This is irrespective of age, education, or socio-economic status. The paradigm presented in this book is grounded in the firm belief that we can, and must, be the change we want.

Looking at the multiple dimensions that shape human existence it appears that their continued interplay has influence on 1) the evolution that occurs inside of each dimension, both in the individual sphere (soul, heart, mind, body); and collectively (micro, meso, macro, meta); and on 2) the course of action that derives from the combined effect of this double four-dimensional dynamic.

\section{A Brief Overview}

Purpose for Power (P4P) gives individuals tools to identify and pursue meaning. Connecting to purpose enables individuals to unlock their inherent power to overcome challenges and thrive despite these challenges. Primary audiences and beneficiaries are aid workers, young people, the elderly, teachers, and social workers. Central entry points are school curricula, parental education programs, retirement residences, and employee well-being programs. It is anchored in the soul.

To trigger the turn from vicious to virtuous Purpose for Power consists of a fourtrack approach which combines theory and praxis: 1) Training of caregivers in selfawareness, emotional intelligence, stress management and personal leadership. Participants get an understanding of the science underpinning the approach and experience its application first-hand. 2) Design of a curriculum with and by these participants that is in line with the needs of their audiences and the context of implementation. 3) Execution of the curriculum, accompanied by ongoing monitoring to facilitate adjustment in line with arising needs, followed by the evaluation of mile-stone components to learn from experience, and allow for refinement over time. 4) Coaching on the job and peer-topeer support accompany participants while they apply their new expertise.

Compassion for Change (C4C) offers an approach for institutions that aim to reignite passion and value awareness among their staff. The result is improved staff well-being, motivation, and performance, which go hand in hand with enhanced institutional impact and reputation because staff members practice the principles and values they preach externally. $\mathrm{C} 4 \mathrm{C}$ helps build a bridge between aspirations and mandate, harmonizing individual and institutional missions. Such harmonization is indispensable for 
non-profit organizations that seek to raise public enthusiasm towards a social cause. It is anchored in the heart.

Humanitarian and development organizations must practice what they preach. Those whose mandate it is to make the world a better place must embody their mission values, individually and collectively, internally and externally. This attitude toward being change is anchored in the self-understanding and behaviour of staff. Whether in the context of humanitarian action, development, or local non-profit mandates, Compassion for Change (C4C) serves to reconnect staff with their personal aspiration for life, and through these aspirations to connect with the mission and values of their employer. $\mathrm{C} 4 \mathrm{C}$ contributes to a transformation of institutional culture by reigniting passion and valuing self-awareness among staff. It nurtures a sense of purpose, belonging, and overall wellbeing; engaging everyone, from frontline fieldworkers to those at headquarters, because in order to effectively help others, every employee must be first able to help themselves.

Influence for Impact (i4i) systematically uses and addresses human aspirations, emotions, thoughts, and sensations to induce desire and readiness for change among individuals and the wider public. i4i supports the design of communication and advocacy efforts that assist and guide audiences through the process of understanding a situation to having a personalized feeling about the issue at hand to caring enough about this matter to act and change the status quo. It is anchored in the body, which is the only interface between our internal and external reality.

Influence for Impact offers practical tools to use the mechanics of human decisionmaking to drive prosocial behavior. (Walther 2020a) Based on research and empirical data it promotes changes in existing decision-making architectures, and offers support for the design of new, socially inclusive ones. Playing along the 'Scale of influence' i4i uses different tools for distinct stages of the decision-making process. It combines neutral (Informing) and intentional (Inciting) communication, addressing intellect and emotions. Since the subconsciousness, and prevailing environment, impact individual decisions, these factors are analyzed and systematically influenced (Nudging). Ultimately i4i is anchored in the understanding that individuals are inspired to give their best self if they are exposed to people who are authentic because their beliefs, words and behavior are in synch (Inspiration). i4i nudges decisions that are in the interest of the performer and his environment, boosts the performers ability to maintain this behavior and helps to establish institutional structures to facilitate the repetition of these new behaviors overtime. By combining short-time change at the individual level with long-term institutional transformation $i 4 i$ serves a gradual formation of new behavior patterns that eventually result in new neural pathways in the individual's brain, which makes them permanent habits. And by investing in institutional decisionmaking architectures groups of people undergo this behavior and brain change, which eventually creates new social norms as the new socially inclusive behavior is practiced over time by a large group of people. (Bicchieri 2017) Primary audiences are 'decision makers', who live the consequences of their decisions (consumers), and 'decision takers', whose decisions shape the lives of others, but not necessarily their own (politicians, CEOs, staff of non-profit organizations).

Honesty for Humility $(\mathrm{H} 4 \mathrm{H})$ brings everything together in a framework of authentic leadership. It offers guidance to accompany the process of unveiling the best version of 
each individual. Honest introspection is the central pillar from which everything else flows naturally. Therefore, while seeking to be useful along the way, $\mathrm{H} 4 \mathrm{H}$ acknowledges that the prime step towards leadership must be taken alone by the individual who is ready. One can indicate the path to the bridge, but not carry the passenger over the river. It is anchored in the mind.

Finding and revealing our best self is not about adding more layers, but about removing the existing ones; to uncover what is waiting underneath. The $\mathrm{H} 4 \mathrm{H}$ interview is structured around the four interrelated dimensions of the POZE paradigm which looks at human existence as a result of four dimensions - soul, heart, mind and body, which find their expression as aspirations, emotions, thoughts and sensations. Summarized as Purpose, $\boldsymbol{O}$ m, Zoom, Experience. These four dimensions correspond to the four arenas in which we invest our energy - spiritual development (Growth), relationships (Love), learning and effort (Work), hobbies and recreation (Play). When analyzing our personal past (including what we learned and experienced), present and future before the backdrop of perpetrating universal values, a common thread emerges which connects the dots of our life.

\section{Perspectives}

COVID-19 engulfs all sectors. A sense of doomsday lingers at the back of everyone's mind, mixed with a sense of uncertainty and unease. We want our life back, but the society that we left behind is gone. (Roy 2020). The reality pre-COVID is no longer; and there is no point trying to resuscitate it. The ongoing crisis is a tragedy, and an amazing opportunity. COVID19 unraveled our routines. Never had millions of people around the World an experience that was the same at the same time. Furthermore, while for millions the Pandemic has further aggravated an already harsh struggle for economic survival, for others, lockdowns and physical distancing resulted in empty time. Shaking up our habits, COVID -19 pushed us

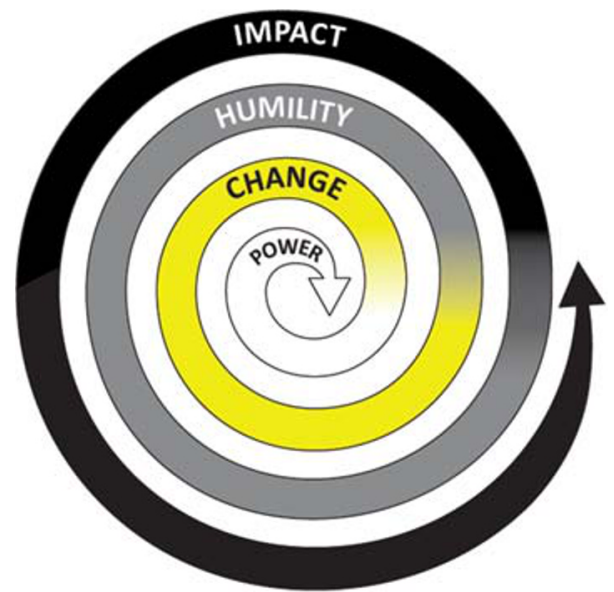

Fig. 2 Everything is connected, from the inside out and from the outside in. Power that is rooted in purpose leads to change that is sustainable and has impact, when the agent of change is driven by compassion and thereby able to genuinely connect with others. Change is sustainable when it comes from a place of personal honesty and humility. When passion, compassion, and honesty are rooted in genuine aspirations, the agents of change have influence because their being and behavior inspire. Being authentic s/he can build change that has impact. This type of social impact engenders in others the desire for purpose, and the quest for their own best self 
into a virgin space to contemplate and react to the unfolding situation with acute awareness, rather than acquired routines. It offered an opening for POZE.

At the macro-level, we are facing a systemic social paradox today. (Walther 2020c). It derives from the combination of a Virus that objectively speaking puts everyone at risk of getting sick and die, and of a layer of massively condoned inequities that have been lingering for centuries. This amalgamation of past and present leads to a status quo whereby the exposure to COVID-19, and the impact on the individual, vary dramatically. The future is haunted by factors that were unsolved and inherent to our social system.

At the meso-level, the Pandemic that afflicts us today has started in a wet market where animals were kept for consumption; catering to our meat-heavy consumption habit. This lifestyle is not conducive to short-term health, nor sustainable for the future of our Planet. (EAT Lancet Commission 2019).

At the micro-level, the social toll that derives from inequity, isolation, emptiness, and depression had put its roots in our lifestyle long before the onset of COVID-19. If everything that happens around us has a counterpart inside, then whatever change we want to trigger outside starts with the journey of personal transformation that individuals, voluntarily, undertake inside.

Looking at the status quo through the prism of the POZE paradigm offers one part of the answer. But paradigms, philosophies, and propositions serve only if they are translated into practice. To not just survive 2020 but thrive in the coming years we must acknowledge that none of us is alone in this; and act accordingly. Our individual wellbeing depends in the long-term on action that we take for the wellbeing of others in the short term. It is a win-win-win-win: If our responsible action helps to reduce contagion, both others and ourselves benefit; the risk is reduced (win-1), then societies can return to a normal operating mode (win-2); furthermore, those who take action for the sake of others benefit from the alignment of their personal values, aspirations and behavior, which is a condition of sustainable subjective wellbeing (win-3). The combination of enhanced wellbeing for the person who takes action and for the person for whom this action is taken for (Santi 2020), is further expanded by the fact that others who observe the behavior of selfless action get inspired to do the same (win-4). The snowball effect of the pay-it-forward dynamic is triggered. ${ }^{6}$

The longstanding paradigm of homo homini lupus est (Latin for 'man is wolf to man') has served for centuries as an unspoken justification for ego-centric behavior; a given that was condoned as unavoidable. Today's scenario may serve to build a new understanding of shared interest. The prevailing situations engulfs all of us indiscriminately; whatever separation existed before COVID-19 took over has become superficial.

\footnotetext{
${ }^{6}$ Various studies have shown that happiness and ideas can spread from person to person. Experiments have shown that beyond such abstract aspects of human experience concrete behavior patterns, such as altruism and cheating can be triggered, with ripple effects, as well. While in the past it was not always clear if people were actually influencing their peers, if all the people that behaved similarly were influenced by the same environments (like an economic meltdown), or if they just choose to assemble with others who think and behave like they do. Based on randomly grouped players the last two explanations were excluded in a 2009 study by Fowler and Christakis. The results suggest that people tend to mimic the actions of those they played with. They could be directly imitating the actions of other players, or they could be looking out for cues that tell them the 'right' or 'normal' way of behaving. Whether it's specific actions or social norms that are spreading, the result is the same - a ripple effect that causes groups of people to act in similar ways (Christakis \& Fowler 2009)
} 


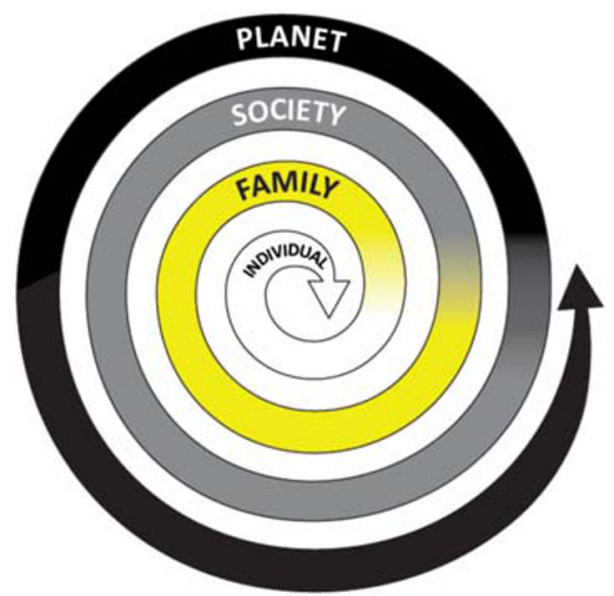

Fig. 3 Everything is connected, from the inside out and from the outside in. The individual is the smallest component of a global system, and part of various 'families' which result from biological, social, or professional constellations. Individuals and families/communities form society, within the contours of nation states, economies, and cultures. These three dimensions are part of Planet Earth, coexisting with nature. Whatever occurs in one dimension has consequences on the others. Individuals influence the communities they are part of, and hereby society, and the planet. Whereas changes at this level impact the dynamics of society and the families and individuals that it is made of

An attitude of homo homini lux est (Latin for 'man is light to man') is needed and at reach. The previously enshrined normality is gone for good. The crisis has opened space to think beyond the conventional line that was previously taken as the horizon. Maybe the plate is bigger than we thought, with space to accommodate not just crumbs but cake for everyone. The size of plate and cake depends on our willingness, our choice, to seize the opportunity. Starting with individual decisions we can generate a new normality where solidarity is the standard, and untamed self-interest shunned. This shift starts with the intellectual understanding (mind) that we are physically part of an interconnected global community (body). This point of departure activates a desire (heart) to get up and involved. Connection generates compassion because it is anchored in our personal aspiration for purpose (soul). Taken together this package enables the mind to envision creative solutions that explode the known.

Changing the world may sound abstract, but it is de facto a very real possibility that involves every single member of 'Society'. Every meso-entity (from families and schools to firms, parties and universities, from public service entities to multi-billion conglomerates) is constituted of myriads of micro-entities (individuals) and depending on their size and nature it may entail multiple meso-entities (Figure 3$)^{7}$ Independently of their size and complexity the entities that are part of the Meso-dimension operate along the same principle of interconnected dimensionality as does the smallest unit in its composition - the human being. How an institution evolves is determined by the action and interplay of the particles that constitute it. Simply said - since an institution is made of

\footnotetext{
${ }^{7}$ While the meso-dimension is sub-national, certain institutions at the meso-level have counterparts at supranational level (i.e. churches, multinational companies). This double nature illustrates the dimensions are inseparable (they are part of a continuum) and the myriad interactions of elements across dimensions. A similar double-sized nature marks the meta-dimension which entails on the one hand supra-national institutions such as the United Nations, and on the other hand the sum of all entities and non-anthropocentric spheres such as Nature.
} 
individuals, its institutional identity (internal) and organizational operation (external) derive from the identity and action of the people who work in it. Since individuals (micro) and institutions (meso) shape the macro-dimension, and are major components of the meta-dimension, the post-COVID-19 Society hinges on the compass that sets the course within these two spheres of life.

\section{The Body Is our Interface with the World}

As the present crisis unfolds this physical crossing-point between our inside and the outside, is becoming a source of acute anxiety for many. From a door that allows us to share and connect, it has been gradually morphing into a barrier. We can transform our physical interface from a source of fear into a well of hope; for ourselves and others. Cooperation may appear to go against our ingrained instinct of purveying first to our own needs. However, supporting others in an effort of sharing is part of our DNA. It is the reason why humankind has reached the present stage of evolution. (Nowak 2011).

Replacing interpersonal exchanges with physical, mental, and emotional self-isolation is not a sustainable choice. Seeking refuge in our comfort zone, by not merely physically retiring to our own four walls, but mentally and emotionally retracting to the opinions and company of closest kin; those whom we are familiar and comfortable with, is tempting. It may feel like the prime choice in a strange scenario of sweltering uncertainty. We do not have that luxury. Preparing the Society that we want to live in afterwards, personally and collectively, must start now, amid the crises. A life that is worth living is another way to frame the concept of quality of life. Beyond the physical aspects of food, water, safety, health care, education, and shelter - which are the basic minimum that must be ensured for every being on this Planet, we require meaning to find fulfillment (WHOQOL 1999). And fulfillment is a central ingredient of quality of life. Purpose is the compass of life. It conditions our happiness, individually and collectively. (Baumeister et al. 2013).

COVID-19 has brought to light that everything can change from one day to the next. However, building on the four-dimensional paradigm mentioned above, four principles emerge as untouched by the present scenario. These are the central pillars of a postCOVID-19 society that is worth living in.

Purpose conditions human completion, 1) The quest for Purpose is the central driver of human life. 2) Compassion for oneself is a transition to compassion for others, ${ }^{8} 3$ ) Honesty fosters a type of candid creation that is free from wishful thinking, and thus innovation incorporated, 4) Influence on the circumstances that determine our existence derives from the understanding of their interplay; and it optimizes the cooperative dynamics that underpin them.

The interaction of the four internal and the four external dimensions shape our individual and collective existence. ${ }^{9}$ Optimizing it is beneficial to each of us. POZE hopes to help with this optimization to enable everyone to lead a full, safe, happy, and enjoyable life.

\footnotetext{
${ }^{8}$ Self-compassion is a process of self-kindness and accepting suffering as a characteristic of being human. It has positive effects on subjective well-being, happiness, optimism, wisdom, curiosity, agreeableness, and extroversion. (Lindquist et al. 2007). It supports the ability to feel compassion towards another person.

${ }^{9}$ For a detailed explanation of the eight dimensions please see Walther 2020a.
} 


\section{Compliance with Ethical Standards}

Conflict of Interest The authors declare that they have no conflict of interest.

On behalf of all authors, the corresponding author states that there is no conflict of interest.

\section{References}

Baumeister, R. F., Vohs, K. D., Aaker, J. L., \& Garbinsky, E. N. (2013). Some key differences between a happy life and a meaningful life. The Journal of Positive Psychology, 8(6), 505-516. https://doi.org/10. 1080/17439760.2013.830764.

Barrett, L. F. (2006). Solving the emotion paradox: Categorization and the experience of emotion. Personality and social psychology review, 10(1), 20-46.

Barrett, L. F. (2009). The future of psychology: Connecting mind to brain. Perspectives on psychological science, 4(4), 326-339.

Bicchieri, C. (2017). Norms in the wild: how to diagnose, measure, and change social norms. New York, NY: Oxford University Press.

Bzdok, D., Laird, A., Zilles, K., Fox, P. T., Eickhoff, S. (2012). An investigation of the structural, connectional and functional sub-specialization in the human amygdala. Human Brain Mapping.

Cuddy, A. (2015). Presence: Bringing Your Boldest Self to Your Biggest Challenges. New York: Little, Brown.

Damasio, A. R., \& Descartes, R. (1994). Error: Emotion, reason, and the human brain (pp. 350-412). New York: Avon.

Damasio, A.R. (2012). Self comes to mind. Knopf Doubleday Publishing Group.

Dhaliwal, G. (2011). Going with Your Gut. Journal of General Internal Medicine 26(2):107-109

Doidge, N. (2007). The brain that changes itself: Stories of personal triumph from the frontiers of brain science. New York, NY: Viking Press.

Doidge, N. (2011). The Brain that changes itself. Carlton North Vic.

EAT. Commission Food in The Anthropocene: the EAT-Lancet Commission on Healthy Diets From Sustainable Food Systems (2019). Retrieved from thelancet.com/commissions/EAT

Fliesler, N. (2017) Decoding Brain Evolution. Harvard. Retrieved from https://hms.harvard.edu/news/ decoding-brain-evolution

Frankl, V. (1946). Men's search for meaning. Republication by Paperback (2006)

Golemann, D. (1996). Emotional intelligence. Bloomsbury Paperbacks

Gordon, J. (2009). Unstuck: Your Guide to the Seven-Stage Journey Out of Depression. Penguin Books (Reprint)

Gratch, J., Marsella, S. (2003). Modeling Coping Behavior in Virtual Humans: Don't Worry, Be Happy. Proceedings of the International Conference on Autonomous Agents. 2. https://doi.org/10.1145/860575. 860626.

Ibarra, H. (2015). Act Like a Leader, Think Like a Leader. Harvard Business Review Press. (Feb 2015)

Kahneman, D. (2007). Thinking fast and slow. New York: Macmillan Palgrave.

Kahneman, D. (2011). Thinking fast and slow. New York: Farrar, Straus and Giroux

Lehrer, J. (2007). Hearts and Minds. Boston Globe.

Lehrer, J. (2010). How we decide. Boston: Mariner Books: Houghton Mifflin Harcourt

Lindquist, K. A., Wager, T. D., Kober, H., Bliss-Moreau, E., \& Barrett, L. F. (2012). The brain basis of emotion: a meta-analytic review. The Behavioral and brain sciences, 35(3), 121-143. https://doi.org/10. 1017/S0140525X11000446.

Nowak, M. (2011). SuperCooperators: Altruism, Evolution, and Why We Need Each Other to Succeed, with Roger Highfield. Martin Free Press. New York

Plante, T. G. (2012, July 2). Helping Others Offers Surprising Benefits. Psychology Today. Retrieved from https:/www.psychologytoday.com/us/blog/do-the-right-thing/201207/helping-others-offers-surprisingbenefits- 0 .

Ramey, S. (2016, May 23). The Benefits Of Witnessing Acts Of Kindness. Retrieved from https:// exploringyourmind.com/benefits-witnessing-acts-kindness/.

Roy, A. (2020) 'The pandemic is a portal' Financial Times (April 2020). Retrieved from https://www.ft.com/ content/10d8f5e8-74eb-11ea-95fe-fcd274e920ca

Santi, J. (2020). The Secret to Happiness Is Helping Others. Times 
Veenstra, L., Schneider, I., \& Koole, S. (2017). Embodied mood regulation: the impact of body posture on mood recovery, negative thoughts, and mood-congruent recall. Cognition and Emotion, 1361-1376.

Walther, C. (2020a). Development, Humanitarian Aid and Social Welfare. Purpose for Power. Macmillan Palgrave/Springer Nature.

Walther, C. (2020b). Humanitarian Work, Social Change and Human behavior. Compassion for Change. Macmillan Palgrave/Springer Nature

Walther, C. (2020c). Development and Connection in times of Covid. Corona's Call for Conscious Choices. Macmillan Palgrave/Springer Nature.

World Health Organization (1999). WHOQOL: Measuring Quality of Life. Annotated Bibliography WHO/ MNH/MHP/98.4. Rev.2

Publisher's Note Springer Nature remains neutral with regard to jurisdictional claims in published maps and institutional affiliations.

Cornelia C. Walther, PhD (law), Affiliations: Deakin University, UNICEF, POZE Network. Cornelia C. Walther combines praxis and research. As a humanitarian practitioner, Cornelia worked for nearly two decades with UNICEF and the World Food Program in large scale emergencies in West Africa, Afghanistan, and Haiti, mostly operating as head of communication. In 2020 three of her books are published by Palgrave/ Springer, 'Development, humanitarian action and social welfare, followed by 'Humanitarian work, social change and human behavior' and 'Development and Connection in times of COVID'. For further information about POZE please see https://www.poze.cc. 